\title{
Timing of secondhand smoke, pet, dampness or mould exposure and lung function in adolescence
}

\author{
Edith B Milanzi (1) , ${ }^{1}$ Gerard H Koppelman, ${ }^{2,3}$ Henriette A Smit, ${ }^{4}$ Alet H Wijga, ${ }^{5}$ \\ Judith M Vonk, ${ }^{2,6}$ Bert Brunekreef, ${ }^{1,4}$ Ulrike Gehring ${ }^{1}$
}

\begin{abstract}
- Additional material is published online only. To view please visit the journal online (http://dx.doi.org/10.1136/ thoraxjnl-2019-213149).

${ }^{1}$ Institute for Risk Assessment Sciences (IRAS), Utrecht University, Utrecht, The Netherlands

${ }^{2}$ Groningen Research Institute for Asthma and COPD (GRIAC) University Medical Center Groningen, Groningen, The Netherlands

${ }^{3}$ Department of Pediatric Pulmonology and Pediatric Allergology, Beatrix Children's Hospital, University Medical Center Groningen, Groningen, The Netherlands

${ }^{4}$ Julius Center for Health Sciences and Primary Care University Medical Center Utrecht, Utrecht, The Netherlands

${ }^{5}$ Centre for Nutrition, Prevention and Health Services, National Institute for Public Health and the Environment (RIVM), Bilthoven, The Netherlands ${ }^{6}$ Department of Epidemiology, University Medical Center Groningen, University of Groningen, Groningen, Netherlands
\end{abstract}

Correspondence to Dr Ulrike Gehring, Institute for Risk Assessment Sciences (IRAS), Utrecht University,

Utrecht 3508TD, The Netherlands; U.Gehring@uu.nl

Received 28 January 2019 Revised 2 October 2019 Accepted 3 October 2019 Published Online First 20 November 2019

\section{Check for updates}

(C) Author(s) (or their employer(s)) 2020. No commercial re-use. See rights and permissions. Published by BMJ.

To cite: Milanzi EB, Koppelman GH, Smit HA, et al. Thorax

2020;75:153-163

\section{ABSTRACT}

Background The relevance of timing of exposure in the associations of secondhand tobacco smoke (SHS), pets, and dampness or mould exposure with lung function is unclear. We investigated the relevance of timing of these exposures for lung function in adolescence.

Methods We used data from participants of the Dutch Prevention and Incidence of Asthma and Mite Allergy (PIAMA) cohort with spirometric measurements at ages 12 and 16 years $(n=552)$. Data on residential exposure to SHS, pets, and dampness or mould were obtained by repeated parental questionnaires. We characterised timing of exposure through longitudinal patterns using latent class growth modelling and assessed associations of these patterns with FEV and FVC at ages 12 and 16 and FEV and FVC growth between ages 12 and 16 using linear regression models.

Results Childhood SHS exposure was associated with reduced FEV growth/year $(95 \% \mathrm{CI})(-0.34 \%(-0.64 \%$ to $-0.04 \%)$ ). Late childhood and early life pet exposure was associated with increased $\mathrm{FEV}_{1}$ growth $(0.41 \%$ $(0.14 \%$ to $0.67 \%))$ and reduced FVC growth $(-0.28 \%$ $(-0.53 \%$ to $-0.03 \%))$, respectively, compared with very low exposure. Early life dampness or mould exposure was associated with reduced lung function growth. All time windows of SHS exposure tended to be associated with lower attained lung function and pet exposure tended to be associated with higher FEV .

Conclusion SHS exposure during childhood could lead to reduced lung function growth and lower attained lung function in adolescence. While pet exposure in late childhood may not adversely affect lung function, early childhood pet exposure may slow down FVC growth in adolescence.

\section{INTRODUCTION}

Household environmental exposures such as secondhand tobacco smoke (SHS), pets, and dampness or mould are modifiable risk factors for adverse respiratory health effects and lung function deficits in children. ${ }^{1}$

Associations of SHS exposure with lung function in children have been reported across cross-sectional and longitudinal studies, ${ }^{2-8}$ but evidence is inconsistent. While some studies have reported associations of early life SHS exposure with lower lung function, ${ }^{910}$ another study has reported no adverse associations of current SHS exposure between 9 and 15 years with lung function in adolescents aged 9-15 except in wheezing children. ${ }^{11}$ SHS exposure during infancy was associated with reduced growth

\section{Key messages}

What is the key question?

- How does timing of exposure to secondhand smoke (SHS), pets, and dampness or mould relate to lung function in adolescence?

What is the bottom line?

- Exposure to SHS in all time windows until age 12 could lead to lower lung function and reduced lung function growth towards adolescence. Pet exposure in late childhood may lead to higher attained lung function and increased lung function growth in adolescence, but early life pet and dampness or mould exposure may have adverse effects on lung function growth.

Why read on?

- Our study points to the importance of timing of exposure to SHS, pets, and dampness or mould throughout the life course in relation to lung function in adolescence, which is rarely investigated. To our knowledge, it is also the first study to investigate associations of pet and dampness or mould exposure with lung function growth beyond childhood.

of pulmonary function in children aged $8-17$ years ${ }^{12}$ and in adolescent girls only ${ }^{9}$ in some studies, but another study has also reported no associations of SHS exposure with lung function growth except in male children with lower lung function at baseline aged $5-15$ years. $^{13}$

Few studies have investigated associations of pet exposure with lung function in childhood and adolescence. The Avon Longitudinal Study of Parents and Children (ALSPAC) study showed no associations between pet exposure and $\mathrm{FEV}_{1}$ and FVC at 8 years, ${ }^{14}$ but current pet exposure was associated with lower $\mathrm{FEV}_{1}$ and FVC in 11-year-olds in the Seven Northeastern Cities (SNEC) study. ${ }^{15}$ Another study investigated association of pet exposure with lung function in adolescence and found dog and/or cat exposure to be associated with higher lung function in asthmatic girls. ${ }^{1}$ None of these studies, however, assessed associations of pet exposure with lung function growth.

There is limited literature on associations of dampness or mould exposure with lung function. Small reductions in lung function have been reported for current dampness or mould exposure 


\begin{tabular}{|c|c|c|}
\hline \multirow[b]{2}{*}{ Characteristics } & \multicolumn{2}{|c|}{ Study population $(n=552)$} \\
\hline & $(\mathrm{n} / \mathrm{N})$ & $(\%)$ \\
\hline \multicolumn{3}{|l|}{ Parental allergy } \\
\hline $\begin{array}{l}\text { Allergic mother } \\
\text { Allergic father }\end{array}$ & $\begin{array}{l}178 / 552 \\
187 / 551\end{array}$ & $\begin{array}{l}32.2 \\
33.9\end{array}$ \\
\hline Boys & $251 / 552$ & 45.4 \\
\hline Presence of pets at 1 year & $226 / 489$ & 41.1 \\
\hline Dampness or mould at 1 year & $49 / 540$ & 9.1 \\
\hline Breast feeding $>12$ weeks & $330 / 552$ & 59.7 \\
\hline Gas cooking at 3 months & $471 / 549$ & 85.8 \\
\hline $\begin{array}{l}\text { Maternal smoking during } \\
\text { pregnancy }\end{array}$ & $68 / 548$ & 12.4 \\
\hline Indoor SHS exposure at 1 year & 109/551 & 19.7 \\
\hline \multicolumn{3}{|l|}{ Parental education } \\
\hline $\begin{array}{l}\text { Low } \\
\text { Intermediate } \\
\text { High }\end{array}$ & $\begin{array}{l}38 / 552 \\
167 / 552 \\
347 / 552\end{array}$ & $\begin{array}{l}6.8 \\
30.2 \\
62.8\end{array}$ \\
\hline $\begin{array}{l}\text { Parental country of birth } \\
\text { (Netherlands) }\end{array}$ & $530 / 545$ & 97.2 \\
\hline Asthma until 8 years & $129 / 552$ & 23.3 \\
\hline \multicolumn{3}{|c|}{$\begin{array}{l}\text { Respiratory infections } 3 \text { weeks before lung function } \\
\text { measurement }\end{array}$} \\
\hline $\begin{array}{l}12 \text { years } \\
16 \text { years }\end{array}$ & $\begin{array}{l}182 / 552 \\
233 / 552\end{array}$ & $\begin{array}{l}32.9 \\
42.2\end{array}$ \\
\hline Active smokers at age $14 / 16$ years & $44 / 552$ & 7.9 \\
\hline
\end{tabular}

SHS, secondhand smoke.

in children aged 6-12 years. ${ }^{16}$ No study has investigated associations of dampness or mould exposure with lung function growth in adolescence.

The inconsistency observed in the aforementioned studies could be attributed to the different ranges of ages studied, different exposure assessments and different study designs. Currently, focus on associations of longitudinal patterns of SHS, pet, and dampness or mould exposures with lung function and lung function growth is rare. However, it may give insights into relevance of timing of exposure, potential windows of susceptibility and consequently windows of opportunity for prevention of lung function growth deficits, which have long-term health consequences beyond adolescence. ${ }^{17}$

We aimed to investigate associations of timing of SHS, pets, and dampness or mould exposure with lung function growth from ages 12 to 16 and lung function level attained at ages 12 and 16 using longitudinal patterns of exposure from pregnancy until 12 years. Potential modifications of associations by sex were explored as these have been suggested for $\mathrm{SHS}^{9}$ and pet exposure. $^{15}$

\section{METHODS}

Data were obtained from the Dutch population-based Prevention and Incidence of Asthma and Mite Allergy (PIAMA) birth cohort study that has been described previously in detail. ${ }^{18}$ In brief, pregnant women were recruited and the baseline study population consisted of 3963 children born between 1996 and 1997. Information on residential exposures, health and lifestyle characteristics was obtained by parental questionnaires completed during pregnancy, 3 months after birth, annually from age 1 to 8 , and then at ages $11,14,16$ (children who participated
Table 2 Age, anthropometric measures and lung function measurements

\begin{tabular}{lrrr}
\hline Variable & \multicolumn{1}{c}{$\begin{array}{l}\text { Age 12 } \\
\text { (mean, SD) }\end{array}$} & \multicolumn{1}{c}{$\begin{array}{l}\text { Age 16 } \\
\text { (mean, SD) }\end{array}$} & \multicolumn{1}{c}{$\begin{array}{l}\text { Mean difference } \\
\text { (SD) }\end{array}$} \\
\hline Age (years) & $12.6(0.3)$ & $16.3(0.2)$ & $3.7(0.4)$ \\
\hline Weight $(\mathrm{kg})$ & $48.2(8.6)$ & $64.1(9.9)$ & $15.9(7.4)$ \\
\hline Height $(\mathrm{cm})$ & $160.4(7.5)$ & $175.5(8.5)$ & $15.1(7.9)$ \\
\hline FEV $_{1}(\mathrm{~mL})$ & $2733(434)$ & $3939(705)$ & $1206(163)$ \\
\hline FVC $(\mathrm{mL})$ & $3244(511)$ & $4710(847)$ & $1466(191)$ \\
\hline Girls $(\mathrm{n}=301)$ & & & \\
\hline Age $($ years $)$ & $12.7(0.4)$ & $16.3(0.2)$ & $3.6(0.5)$ \\
\hline Weight $(\mathrm{kg})$ & $48.7(8.6)$ & $60.8(8.7)$ & $12.1(5.9)$ \\
\hline Height $(\mathrm{cm})$ & $160.8(7.2)$ & $170.2(6.1)$ & $9.4(4.8)$ \\
\hline FEV $(\mathrm{mL})$ & $2751(422)$ & $3517(440)$ & $766(316)$ \\
\hline FVC $(\mathrm{mL})$ & $3218(509)$ & $4170(517)$ & $952(370)$ \\
\hline Boys $(\mathrm{n}=251)$ & & & \\
\hline Age $($ years $)$ & $12.6(0.3)$ & $16.3(0.2)$ & $3.7(0.5)$ \\
\hline Weight $(\mathrm{kg})$ & $47.4(8.5)$ & $67.9(9.9)$ & $20.5(6.4)$ \\
\hline Height $(\mathrm{cm})$ & $159.9(7.9)$ & $181.7(6.5)$ & $21.8(5.3)$ \\
\hline FEV $(\mathrm{mL})$ & $2711(448)$ & $4444(626)$ & $1733(435)$ \\
\hline FVC $(\mathrm{mL})$ & $3274(513)$ & $5359(697)$ & $2085(506)$ \\
\hline
\end{tabular}

in the medical examination) and 17. Medical examinations were performed at ages 8,12 and 16. The current study population consists of children with lung function measurements at both ages 12 and 16, and data on SHS, pet and/or dampness or mould exposure $(n=552)$.

\section{Exposure assessment}

Exposure was defined based on questionnaires administered from pregnancy (SHS and pets) or from 3 months (dampness or mould) until age 12 .

\section{Secondhand smoke}

SHS exposure during pregnancy was defined as maternal smoking during the first 4 weeks of pregnancy. After birth until age 12, SHS exposure was defined as any smoking in the child's home, assessed by the question "Does anyone smoke in the house" (yes, yes but less than once a week, never) dichotomised as yes (for all yes responses) and no (never).

\section{Pet exposure}

The question "Do you keep a dog/cat/rodent indoors?" (yes, no) asked separately for each pet was used to assess exposure to pets.

\section{Dampness or mould}

The question "Have you seen any moisture stains or mould on the ceiling or walls in the last 12 months?" (yes, no) was used to assess dampness or mould exposure. Assessment was restricted to presence of dampness or mould in the living room or child's bedroom because this is where children are expected to spend most of their time.

\section{Longitudinal patterns of exposure}

Time-varying responses to questions on SHS, pets, and dampness or mould exposures were characterised into longitudinal exposure patterns from pregnancy until age 12 using Latent Class Growth Modelling (TRAJ procedure in SAS V.9.4, Cary, USA). ${ }^{19}$ The procedure allocates individuals into patterns based 

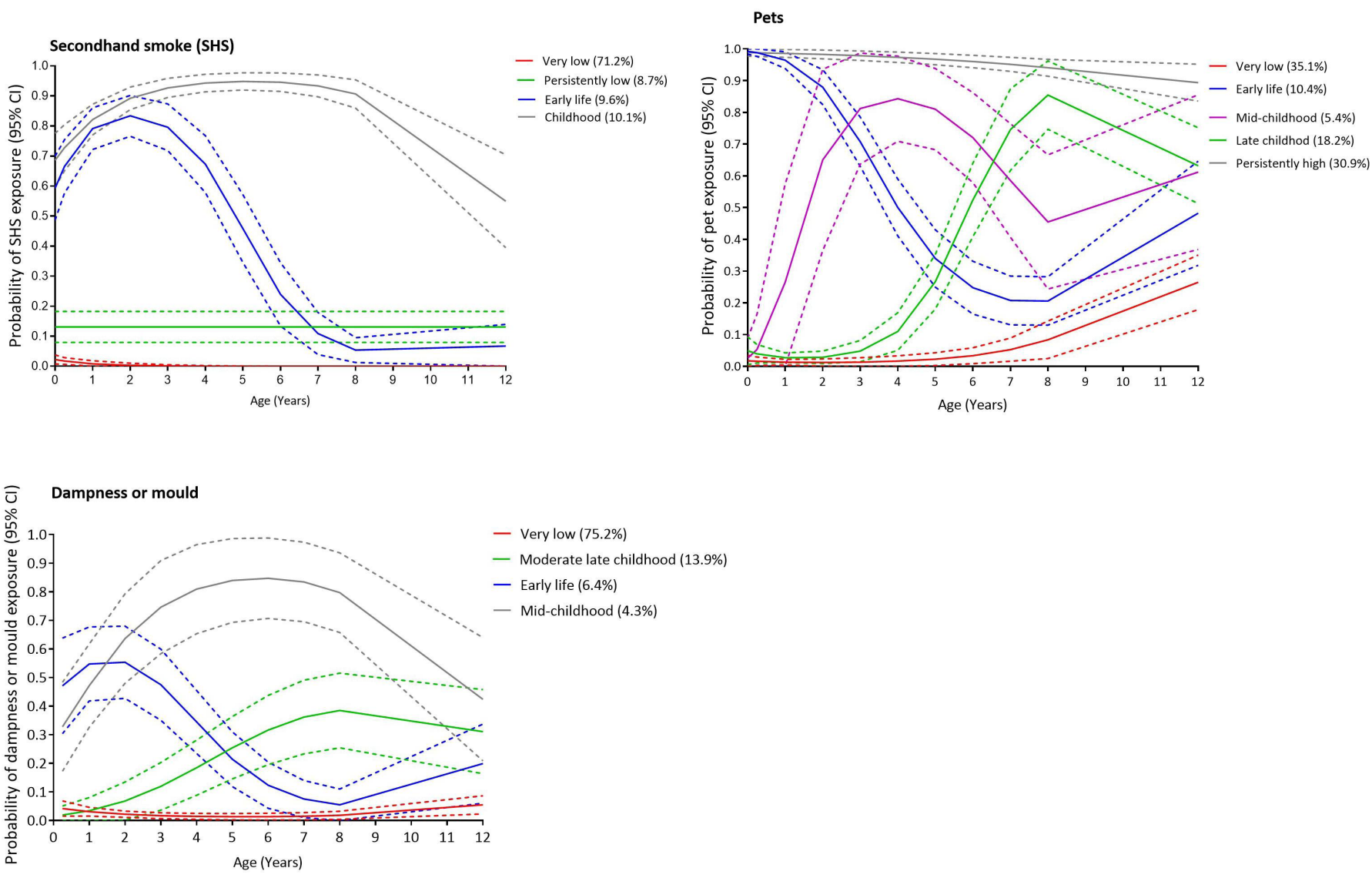

Figure 1 Longitudinal patterns of SHS, pets, and dampness or mould exposure with pattern frequencies.

on posterior probabilities. To establish the number of exposure patterns, we first assumed one constant pattern by specifying the intercept and added additional patterns until model performance according to the Bayesian Information Criterion (BIC) was no longer improved. Final choice of number of patterns was based on model with smallest BIC and practical plausibility, for example, groups with less than $2 \%$ class membership or groups with similar shapes were combined as these did not provide new information regarding exposure patterns. All children with data on exposure for at least one time point (missing data for one or more, but not all time points) were included in the latent class modelling procedure.

\section{Lung function}

Lung function ( $\mathrm{FEV}_{1}$ and $\mathrm{FVC}$ ) measurements were performed during medical examinations at ages 12 and 16. Details of the measurements have been described elsewhere. ${ }^{2021}$ A total of 1292 and 721 children had successful lung function measurements at ages 12 and 16, respectively, and 552 had measurements at both ages (online supplementary figure E1). Percentage of annual lung function growth was modelled by taking log of the difference in lung function between ages 12 and 16 and then dividing this difference by time (in years) between the two measurements. We used EasyOne spirometers (NDD Medical Technologies, Switzerland) at age 12 and both Jaeger Masterscreen pneumotachograph (CareFusion, Yorba Linda, California, USA) and EasyOne spirometers at age $16 .^{21}$ All measurements were performed following American Thoracic Society/European Respiratory Society recommendations. ${ }^{22}$ At least three acceptable manoeuvres were required for each child. We also included measurements, which did not meet these criteria (difference between largest and next largest value $\leq 150 \mathrm{~mL}$ for $\mathrm{FEV}_{1}$ and FVC) but were obtained from technically acceptable trials with differences between largest and next largest values for $\mathrm{FEV}_{1}$ and FVC $\leq 200 \mathrm{~mL}(\mathrm{n}=125$ at age 12 and $\mathrm{n}=67$ at age 16$)$.

\section{Potential confounders}

The following a priori selected variables that were obtained during the medical examination and from parental questionnaires were considered as potential confounders based on evidence from literature on their relationship with lung function and/or the respective exposures: sex, height, weight and age at the time of medical examination were included as predictors of lung function ${ }^{22}$; height, weight and age were log-transformed as described elsewhere ${ }^{2324}$ in view of the strongly non-linear relationships between lung function and these factors. Maternal and paternal allergy (defined as positive if the father and/or mother ever had asthma, were allergic to house dust, house dust mite or pets, or had hay fever) was adjusted for as it predisposes to asthma and allergic disease and may be associated with (avoidance of) exposure. ${ }^{2526}$ We also adjusted for respiratory infections during the 3 weeks before lung function measurement as this may influence lung function, breast feeding at 12 weeks (yes/ no) because breast feeding has been shown to enhance lung volume in children, ${ }^{27}$ parental country of birth (Netherlands, yes/no) to account for ethnic differences in lung function, ${ }^{22}$ as well as gas cooking at 3 months (yes/no), estimated annual average outdoor $\mathrm{NO}_{2}$ concentrations at the birth address and birth weight because these are considered/known risk factors of lower lung function. ${ }^{21}{ }^{28-30}$ Models with patterns of pet exposure were additionally adjusted for maternal smoking during pregnancy, SHS exposure and presence of dampness or mould 
Table 3 Associations of longitudinal patterns of SHS, pets, and dampness or mould exposure with per cent difference in annual growth of FEV and FVC from ages 12 to 16

\begin{tabular}{|c|c|c|c|c|}
\hline & \multicolumn{2}{|c|}{$\%$ difference in $\mathrm{FEV}_{1}$ growth/year $(95 \% \mathrm{Cl})$} & \multicolumn{2}{|c|}{$\%$ difference in FVC growth/year $(95 \% \mathrm{Cl})$} \\
\hline & Crude $^{\alpha}(n=552)$ & Adjusted $^{\beta}(n=525)$ & Crude $^{\alpha}(n=552)$ & Adjusted $^{\beta}(n=525)$ \\
\hline \multicolumn{5}{|l|}{ SHS } \\
\hline Early life vs very low & $0.15(-0.13$ to 0.44$)$ & 0.31 (0.01 to 0.61 ) & $0.06(-0.22$ to 0.35$)$ & $0.32(0.03$ to 0.62$)$ \\
\hline Childhood vs very low & $-0.48(-0.76$ to -0.19$)$ & $-0.34(-0.64$ to -0.04$)$ & $-0.28(-0.56$ to -0.00$)$ & $-0.04(-0.33$ to 0.26$)$ \\
\hline Mid-childhood vs very low & $-0.23(-0.52$ to 0.07$)$ & $-0.09(-0.40$ to 0.21$)$ & $-0.16(-0.45$ to 0.13$)$ & $-0.04(-0.34$ to 0.26$)$ \\
\hline Late childhood vs very low & $0.18(-0.07$ to 0.43$)$ & 0.41 (0.14 to 0.67 ) & $-0.46(-0.70$ to -0.21$)$ & $-0.14(-0.39$ to 0.12$)$ \\
\hline Persistently high vs very low & $-0.32(-0.51$ to -0.14$)$ & $-0.26(-0.46$ to -0.06$)$ & $-0.43(-0.61$ to -0.25$)$ & $-0.33(-0.53$ to -0.14$)$ \\
\hline \multicolumn{5}{|l|}{ Dampness or mould } \\
\hline
\end{tabular}

$\alpha$ Adjusted for sex, log transformations of differences in height, weight and age between the 12-year and 16-year lung function measurements. $\beta$ Adjusted for sex, log transformations of differences in height, weight and age between the 12-year and 16-year lung function measurements, parental education, maternal and paternal allergy, breast feeding at 12 weeks, maternal smoking during pregnancy, indoor SHS at 1 year (except in models with SHS exposure), use of gas for cooking at 3 months, annual average $\mathrm{NO}_{2}$ concentration at the birth address, birth weight, dampness or mould in the child's home at 1 year (except in models with dampness or mould exposure), pets in the home at 1 year (except in models with pet exposure), respiratory infections in the past 3 weeks before medical examination.

SHS, secondhand smoke.

in the child's home during the first year; models with patterns of SHS exposure were additionally adjusted for pets and dampness or mould in the child's home during the first year; and models with patterns of dampness or mould exposure were additionally adjusted for maternal smoking during pregnancy, SHS and pets in the child's home during the first year. These mutual adjustments of the respective exposures (defined as binary variables, yes/no) were performed to take into account the relationship of an exposure and lung function in the presence of the other two respective exposures.

\section{Statistical analyses}

We used linear regression models to assess associations of longitudinal exposure patterns with growth in $\mathrm{FEV}_{1}$ and $\mathrm{FVC}$ between 12 and 16 years and attained levels of $\mathrm{FEV}_{1}$ and $\mathrm{FVC}$ at ages 12 and $16 . \mathrm{FEV}_{1}$ and $\mathrm{FVC}$ were log-transformed because of their strong non-linear relationships with age, height and weight as reported in the Harvard Six Cities study ${ }^{23}$ and in other studies including our own. ${ }^{202431}$ Longitudinal exposure patterns were included as independent variables. Associations with lung function growth are expressed as per cent difference in growth per year and associations with attained level of lung function at ages 12 and 16 are expressed as per cent difference; both relate to the geometric means of the lung function variables and were calculated from estimated regression coefficients $\beta$ as $\left(e^{\beta}-1\right) \times 100$. Exposure patterns defined as 'very low' were used as reference categories. To account for uncertainty in allocation of patterns, we created multiple records for each participant (one for each exposure pattern) and weighted records by respective posterior probabilities in all analyses. Crude models assessing lung function growth were adjusted for sex, log transformations of differences in height, weight and age between lung function measurements and crude models of attained level of $\mathrm{FEV}_{1}$ or FVC at ages 12 and 16 were adjusted for sex, log transformations of height, weight and age. All models were further adjusted for all other mentioned confounders in adjusted analyses. We used the STROBE (Strengthening the Reporting of Observational Studies in Epidemiology) cohort reporting guidelines. ${ }^{32}$ Statistical analyses were performed in SAS V.9.4 at 0.05 level of significance.

\section{Sensitivity analyses}

As part of sensitivity analyses, we investigated sex interactions as development and progression of certain common respiratory diseases has been found to differ by sex. ${ }^{3334}$ We also performed stratified analyses by parental allergy status. We excluded children who reported respiratory infections in the previous 3 weeks before lung function measurements. We also repeated analyses after excluding both childhood asthmatics until age 8 and children whose parents had removed pets because of any family member allergies $(n=129)$ as it has been suggested that childhood asthma may influence pet avoidance and this may distort associations of pet exposure. ${ }^{35}$ In addition, we repeated analyses excluding active smokers at either age 14 or $16(n=44)$.

\section{RESULTS}

Table 1 shows study population characteristics. In total, $12.4 \%$ of the children were exposed to maternal smoking during pregnancy; $41.1 \%$ owned pets, and $9.1 \%$ were exposed to dampness or mould in the first year of life. Mean (SD) FEV was $2733(434) \mathrm{mL}$ and $3939(705) \mathrm{mL}$ at ages 12 and 16, respectively. Mean (SD) FVC was 3244 (511) $\mathrm{mL}$ and 4710 (847) $\mathrm{mL}$ at ages 12 and 16, respectively (table 2). Box plots indicating distributions of lung function values across different patterns of exposures of interest have been presented in online supplementary figures E2-E4. There were fewer children who owned pets, who were exposed to maternal smoking during pregnancy and more children with highly educated parents in the study population than in the baseline population (online supplementary table E1). Compared with the study population, the excluded population of children with lung function 
Secondhand smoke (SHS)

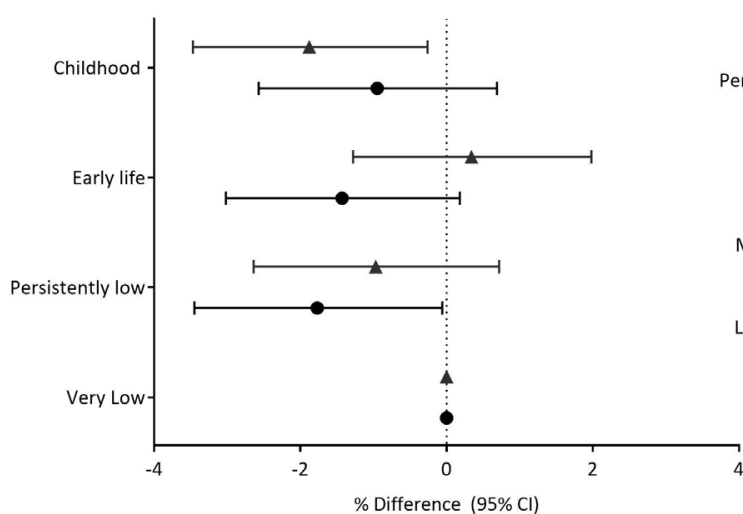

Dampness or mould

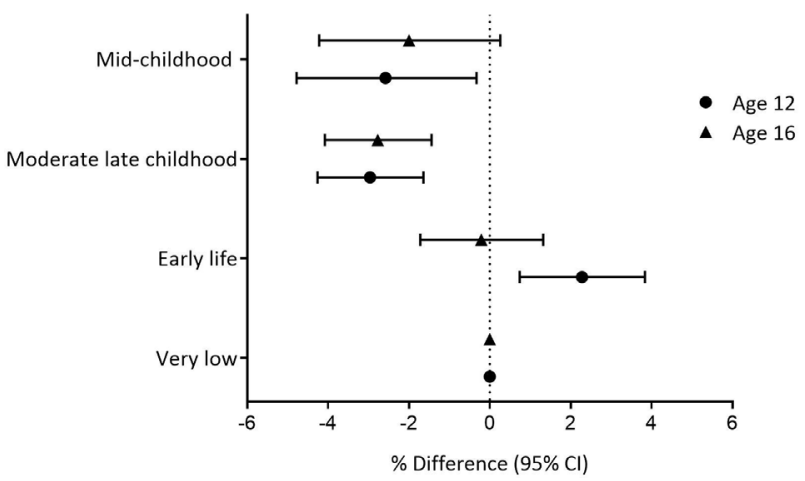

Pets

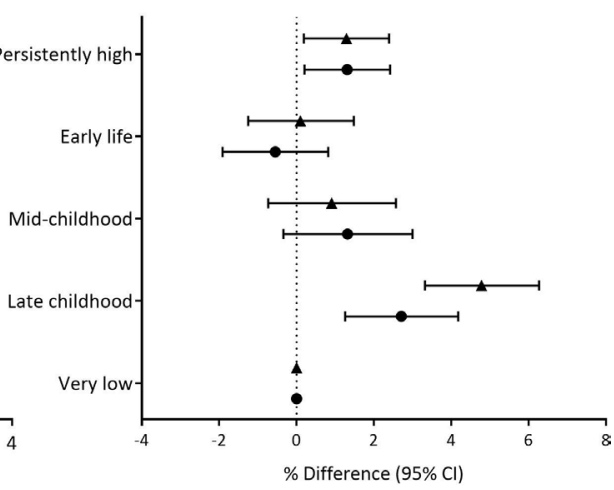

Figure 2 Adjusted associations of longitudinal patterns of SHS, pets, and dampness or mould exposure with FEV, level (\% difference) at ages 12 and 16. Adjusted for sex, height, weight and age, parental education, maternal and paternal allergy, breast feeding at 12 weeks, maternal smoking during pregnancy, indoor SHS at 1 year (except in models with SHS exposure), use of gas for cooking at 3 months, annual average $\mathrm{NO}_{2}$ concentration at the birth address, birth weight, dampness or mould in the child's home at 1 year (except in models with dampness or mould exposure), pets in the home at 1 year (except in models with pet exposure), respiratory infections in the past 3 weeks before medical examination.

measurements at age 12 , but not at age 16 had more boys, fewer children breast fed for 12 weeks or more, fewer children exposed to gas cooking, fewer children of low educated parents and more children exposed to SHS during the first year (online supplementary table E1). Online supplementary table E2 presents frequencies of surveys with missing exposure data. More than $92 \%$ of the children had complete SHS and pet exposure data from pregnancy until age $12 ; 76 \%$ of the children had complete dampness or mould exposure data from 3 months until age 12 and $22 \%$ had one missing value for that period. For all three exposures, no more than $1 \%$ of the children had three or more missing values.

We identified four (SHS and dampness or mould) and five (pets) exposure patterns including, for every exposure, a very low probability of exposure pattern throughout childhood, higher probability of exposure in early life and higher probability of childhood exposure (figure 1). We also identified a persistently low exposure pattern of SHS exposure. Univariate associations of patterns of exposure with selected participant characteristics are presented in online supplementary table E3 Very low exposure patterns were generally characterised with children with higher odds of having allergic and/or highly educated parents while high persistent exposure patterns were characterised by children with low educated and/or less allergic parents.
Associations of exposure patterns with lung function growth

Crude associations of exposure patterns with lung function growth and attained lung function were generally similar to adjusted associations (table 3 and, online supplementary file 1 table E4).

Higher probability of childhood SHS exposure was associated with reduced $\mathrm{FEV}_{1}$ growth between ages 12 and 16 (per cent difference in growth/year (95\% CI) $-0.34 \%(-0.64 \%$ to $-0.04 \%)$ ) compared with very low exposure (table 3 ). In contrast, higher probability of early life and persistently low SHS exposure were not negatively associated with lung function growth.

Higher probability of late childhood pet exposure was associated with increased $\mathrm{FEV}_{1}$ growth $(0.41 \%(0.14 \%$ to $0.67 \%)$ ) compared with very low exposure while persistently high and early life pet exposure were associated with reduced FVC growth; $-0.33 \%(-0.53 \%$ to $-0.14 \%)$ and $-0.28 \%(-0.53 \%$ to $-0.03 \%)$, respectively.

Higher probability of early life dampness or mould exposure was associated with both reduced FEV and FVC growth (table 3).

\section{Associations of exposure patterns with lung function level}

We observed lower lung function levels in children with childhood SHS exposure, for example, per cent difference (95\% CI) 

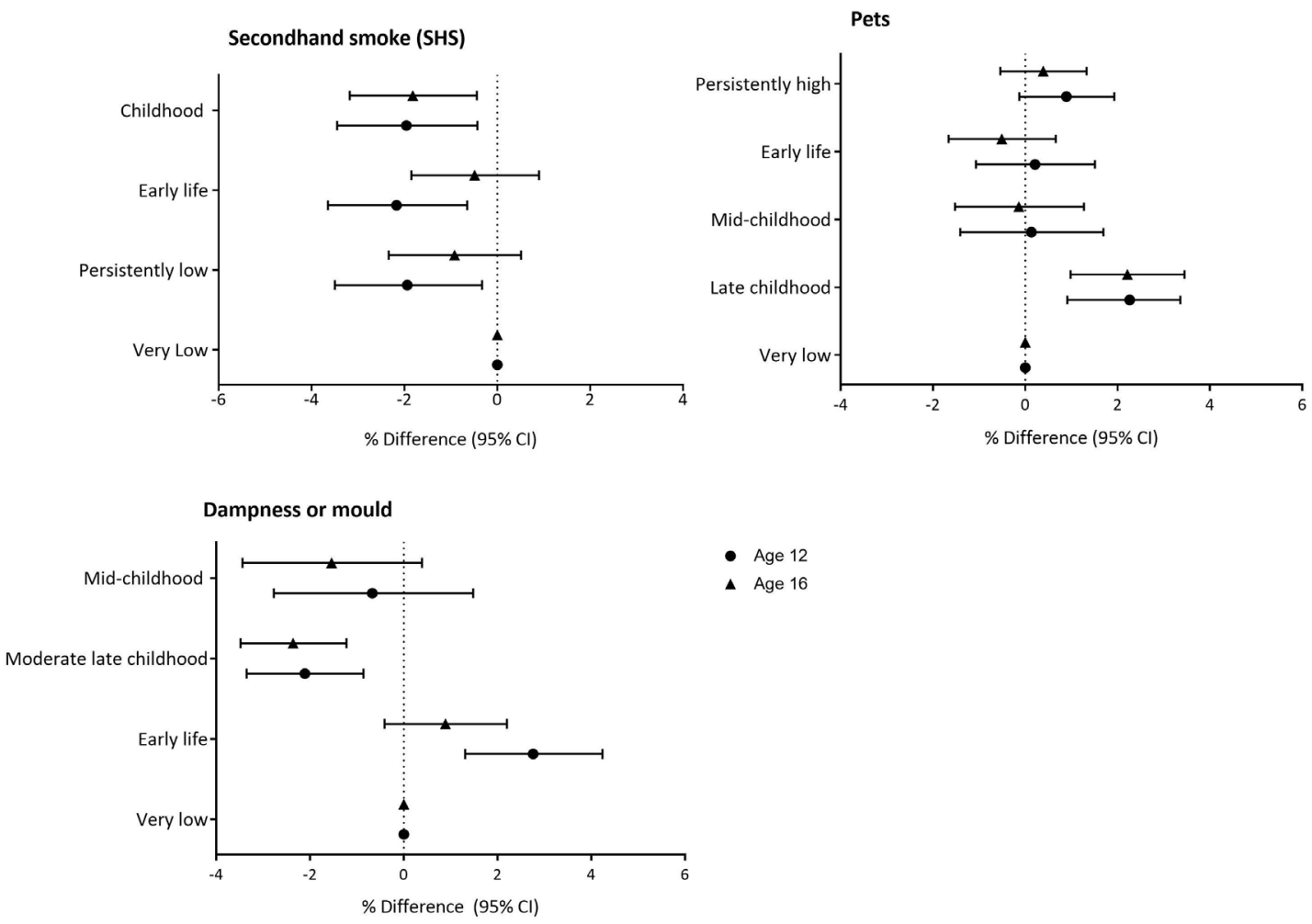

- Age 12

A Age 16

Figure 3 Adjusted associations of longitudinal patterns of SHS, pets, and dampness or mould exposure with FVC level (\% difference) at ages 12 and 16. Adjusted for sex, log transformations of height, weight and age, parental education, maternal and paternal allergy, breast feeding at 12 weeks, maternal smoking during pregnancy, indoor SHS at 1 year (except in models with SHS exposure), use of gas for cooking at 3 months, annual average $\mathrm{NO}_{2}$ concentration at the birth address, birth weight, dampness or mould in the child's home at 1 year (except in models with dampness or mould exposure), pets in the home at 1 year (except in models with pet exposure), respiratory infections in the past 3 weeks before medical examination.
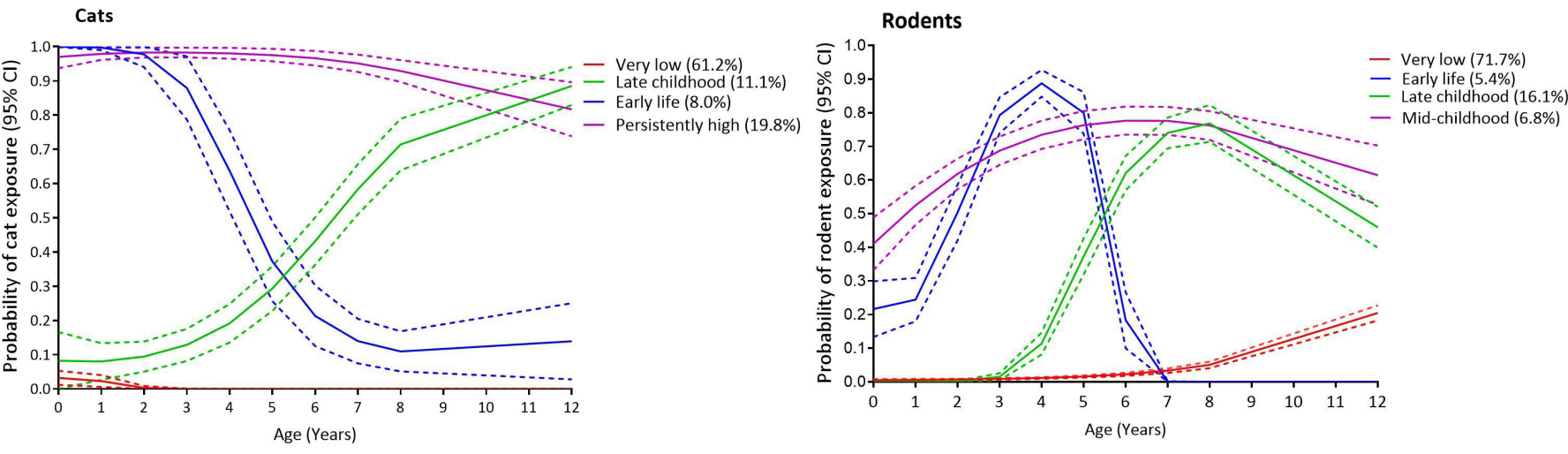

Dogs

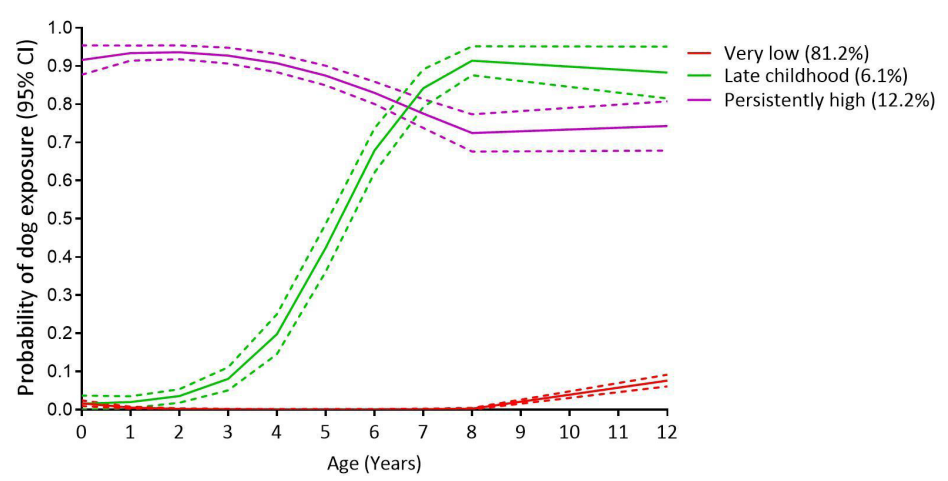

Figure 4 Longitudinal patterns of cat, dog and rodent exposure with pattern frequencies. 
Table 4 Adjusted associations of longitudinal patterns of cat, dog and rodent exposure with annual per cent difference in growth of $\mathrm{FEV}_{1}$ and FVC from ages 12 to 16

\begin{tabular}{|c|c|c|}
\hline$n=524$ & $\begin{array}{l}\% \text { difference in } \mathrm{FEV} \\
\text { growth/year }(95 \% \mathrm{Cl})\end{array}$ & $\begin{array}{l}\% \text { difference in FVC } \\
\text { growth/year }(95 \% \mathrm{Cl})\end{array}$ \\
\hline \multicolumn{3}{|l|}{ Cats } \\
\hline Early life vs very low & $-0.09(-0.38$ to 0.20$)$ & $-0.71(-0.99$ to -0.42$)$ \\
\hline $\begin{array}{l}\text { Late childhood vs very } \\
\text { low }\end{array}$ & 0.41 (0.05 to 0.77 ) & $0.08(-0.25$ to 0.43$)$ \\
\hline $\begin{array}{l}\text { Persistently high vs very } \\
\text { low }\end{array}$ & $-0.46(-0.71$ to -0.22$)$ & $-0.33(-0.55$ to -0.08$)$ \\
\hline \multicolumn{3}{|l|}{ Dogs } \\
\hline $\begin{array}{l}\text { Late childhood vs very } \\
\text { low }\end{array}$ & $-0.18(-0.61$ to 0.26$)$ & -0.34 ( -0.76 to 0.08$)$ \\
\hline $\begin{array}{l}\text { Persistently high vs very } \\
\text { low }\end{array}$ & $-0.26(-0.56$ to 0.05$)$ & $-0.11(-0.40$ to 0.19$)$ \\
\hline \multicolumn{3}{|l|}{ Rodents } \\
\hline $\begin{array}{l}\text { Early childhood vs very } \\
\text { low }\end{array}$ & $-0.75(-1.15$ to -0.35$)$ & $-0.80(-1.19$ to -0.41$)$ \\
\hline $\begin{array}{l}\text { Late childhood vs very } \\
\text { low }\end{array}$ & 0.25 (0.01 to 0.48$)$ & 0.35 (0.12 to 0.58$)$ \\
\hline $\begin{array}{l}\text { Mid-childhood vs very } \\
\text { low }\end{array}$ & $0.13(-0.27$ to 0.52$)$ & $0.28(-0.10$ to 0.67$)$ \\
\hline \multicolumn{3}{|c|}{$\begin{array}{l}\text { Adjusted for sex, log transformations of differences in height, weight and age } \\
\text { between the } 12 \text {-year and } 16 \text {-year lung function measurements, parental education, } \\
\text { maternal and paternal allergy, breast feeding at } 12 \text { weeks, maternal smoking during } \\
\text { pregnancy, indoor secondhand smoke at } 1 \text { year, use of gas for cooking at } 3 \text { months, } \\
\text { annual average } \mathrm{NO}_{2} \text { concentration at the birth address, birth weight, dampness } \\
\text { or mould in the child's home at } 1 \text { year, respiratory infections in the past } 3 \text { weeks } \\
\text { before medical examination. }\end{array}$} \\
\hline
\end{tabular}

$-1.88 \%(-3.47 \%$ to $-0.26 \%)$ for $\mathrm{FEV}_{1}$ at age 16 , as well as persistently low exposure $(-1.77 \%(-3.45 \%$ to $-0.06 \%))$ for $\mathrm{FEV}_{1}$ at age 12 (figure 2, online supplementary table E4). Higher probability of SHS exposure in early life was associated with lower attained levels of FVC especially at age 12 compared with very low probability of SHS exposure (figure 3 ).

Exposure to pets during mid-childhood and late childhood was associated with higher attained levels of lung function, for example, per cent difference $4.78 \%$ (3.32\% to 6.27\%) in $\mathrm{FEV}_{1}$ at age 16 and $2.21 \%(0.98 \%$ to $3.45 \%)$ in $\mathrm{FVC}$ at age 16 for late childhood exposure. All other pet exposure patterns (ie, probability of early life exposure and persistently high exposure) also tended to be associated with higher attained $\mathrm{FEV}_{1}$ and $\mathrm{FVC}$ at both 12 and 16 years (figures 2 and 3, online supplementary table E4).

Moderate late childhood and mid-childhood dampness or mould exposure was associated with lower $\mathrm{FEV}_{1}$ and FVC at ages 12 and 16. In contrast, we observed higher $\mathrm{FEV}_{1}$ and FVC at age 12 with early life dampness or mould exposure (figures 2 and 3, online supplementary table E4).

Figure 4 shows distinct patterns of exposure to cats, dogs and rodents separately. In general, similar patterns of exposure were observed across different pets. Associations of individual pet exposure patterns with lung function were complex. Higher probability of cat and rodent exposure in early life was associated with reduced FEV and FVC growth, but late childhood exposure to these pets was generally associated with higher level of attained FEV 1 and FVC. Dog exposure was generally associated with lower lung function and reduced lung function growth (table 4, figures 5 and 6).

\section{Sensitivity analyses}

Associations between all exposures of interest and lung function growth were inconsistent between boys and girls (online supplementary table E5). Both boys and girls tended to have lower $\mathrm{FEV}_{1}$ and FVC at age 12 with early life exposure to SHS though weaker in girls. Boys tended to have higher $\mathrm{FEV}_{1}$ at age 16 with late childhood pet exposure (eg, $\mathrm{p}$ value of interaction $<0.001$; online supplementary table E6).

We did not observe different associations with SHS exposure patterns for children of allergic and non-allergic parents, except for stronger associations of SHS exposure with lower attained FVC in children of allergic parents (online supplementary tables E7 and E8). All patterns of pet exposure were consistently associated with higher attained lung function at ages 12 and 16 in children of non-allergic parents. Late childhood pet exposure was associated with increased $\mathrm{FEV}_{1}$ growth in children of allergic parents, but persistently high exposure was associated with reduced $\mathrm{FEV}_{1}$ and $\mathrm{FVC}$ growth in this group. There were generally no differences in association for dampness or mould exposure (online supplementary tables E7 and E8).

Excluding children who had respiratory infections during the 3 weeks before lung function measurements did not change results (online supplementary tables E9-E10). Results were similar when we excluded asthmatics and children of parents who reported removal of pets due to family allergies (online supplementary table E11), but a stronger reduction in attained FVC with pet exposure was observed when we excluded active smokers (online supplementary table E12).

\section{DISCUSSION}

In our prospective birth cohort, we assessed the role of different timing of exposure in relation to lung function (growth) using longitudinal exposure patterns. Higher childhood SHS exposure was associated with reduced lung function growth and all periods of SHS exposure until age 12 tended to be associated with lower attained lung function in adolescence. Late childhood and early life pet exposure was associated with increased $\mathrm{FEV}_{1}$ growth and reduced FVC growth, respectively, while all pet exposure periods tended to be associated with higher attained lung function compared with very low pet exposure. Early life exposure to dampness or mould was associated with reduced lung function growth and in contrast early life dampness or mould exposure was associated with higher level of lung function at both ages 12 and 16.

\section{Lung function and SHS}

Our findings suggest that continued exposure to SHS from birth until childhood may lead to reduced $\mathrm{FEV}_{1}$ growth and lower attained lung function in adolescence, indicating possible airway obstruction and reduced lung volume. The associations of continuous SHS childhood exposure with reduced FEV growth are consistent with findings of other longitudinal studies that have studied similar associations. ${ }^{91213}$ SHS exposure was associated with lower attained $\mathrm{FEV}_{1}$ at age 16 as reported in multiple studies. ${ }^{934} 36$ However, only one study addressed different timing of SHS exposure and lung function in adolescence ${ }^{8}$ and reported, in contrast to our study, no significant associations of SHS exposure at 3 months or at age 16 years with lung function at age 16. Likewise, another study reported no significant associations of current SHS exposure between ages 9 and 15 with $\mathrm{FEV}_{1}$ or FVC in children 9-15 years old. ${ }^{11}$ We contribute to the increasing body of evidence that suggests that effects of continued SHS exposure during childhood on lung function can persist throughout childhood and into 

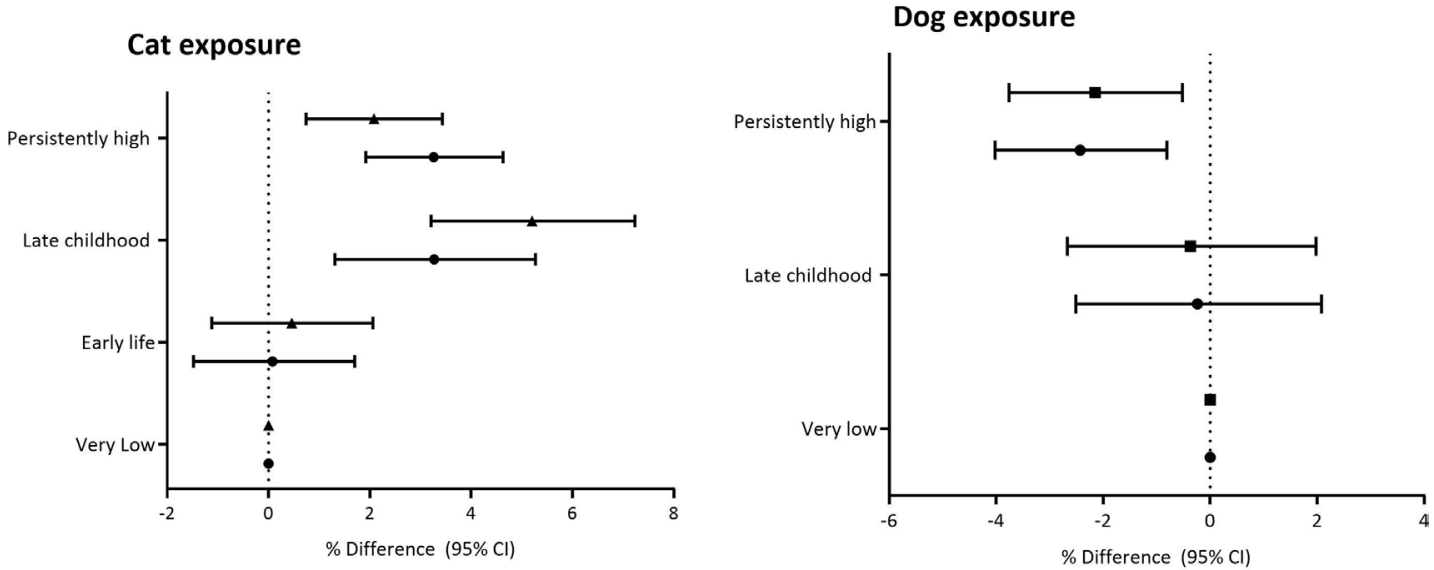

Rodent exposure

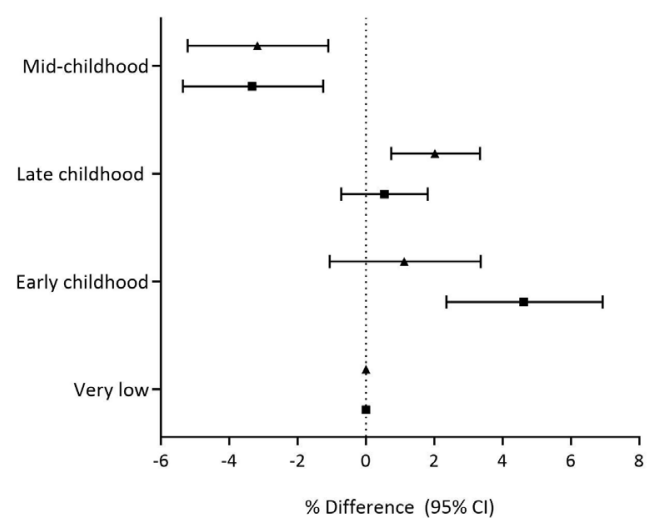

- Age 12

- Age 16

Figure 5 Associations of longitudinal patterns of cat, dog and rodent exposure with FEV level (\% difference) at ages 12 and 16 (adjusted for sex, log transformations of height, weight and age, parental education, maternal and paternal allergy, breast feeding at 12 weeks, maternal smoking during pregnancy, indoor secondhand smoke at 1 year, use of gas for cooking at 3 months, annual average $\mathrm{NO}_{2}$ concentration at the birth address, birth weight, dampness or mould in the child's home at 1 year, respiratory infections in the past 3 weeks before medical examination).

adolescence. $^{2637}$ The observed positive associations of early life SHS exposure with lung function growth in adolescence may point to the possibility that the lungs of children whose parents smoked in early life but quit in early years of the child may benefit from sustained parental smoking abstinence. Exact mechanisms by which SHS affects lung function are unclear, but altered organ maturation and immune function have been suggested though mechanisms may vary across phases of lung growth and development, extending from in utero to completion of lung growth in late adolescence. ${ }^{38}$

\section{Lung function and pets}

Few studies have investigated associations of pet exposure with childhood or adolescent lung function while none have investigated pet exposure and lung function growth. Existing evidence is conflicting as pet exposure has been associated with lower ${ }^{15}$ and higher lung function. ${ }^{1}$ Null associations have also been reported. ${ }^{14}$ Pet exposure in late childhood was associated with increased $\mathrm{FEV}_{1}$ growth and higher $\mathrm{FEV}_{1}$ and FVC in adolescence in our study pointing to either beneficial effects or selection/reverse causation as allergic parents whose children have an increased risk of being allergic may avoid pets (online supplementary table E2). Further investigations on pet avoidance due to early childhood respiratory symptoms showed no association between childhood asthma and rhinitis and pattern membership (online supplementary table E13), suggesting that asthma and rhinitis in early and mid-childhood were not reasons for parents to avoid pets until late childhood in our cohort. In contrast, early life and persistently high exposure to pets was associated with reduced FVC growth which may be partly in line with studies that have reported lower lung function in relation to pet exposure. One study reported associations of cat, dog and rodent exposure with higher lung function in adolescents ${ }^{1}$ and in children. ${ }^{14}$ We observed similar associations with cats and attained $\mathrm{FEV}_{1}$, but early life cat, rodent and all patterns of dog exposure were associated with reduced and lower FVC (growth). Studies have suggested that IgE-associated inflammation responses could be responsible for allergic lung inflammation due to pet exposure, ${ }^{39}$ but this remains controversial as IgE-related mechanisms are also attributed to protective effects of asthma and it is unclear what role this could play in improved lung function. The majority of the parents kept one type of pet at a time, but some parents kept more than one type of pet (online supplementary figure E5). This raises the possibility of pet-pet interactions in relation to lung function, but numbers are too small to explore these interactions in the present study population.

Until now, existing literature focused on pet exposure and lung function in childhood. Our study extends into adolescence and our findings suggest that late childhood pet exposure may be a relevant exposure period in our study but also that high persistent and early life exposure from birth into adolescence may have adverse effects on FVC growth. Presence of pets in the home which has been linked to higher concentrations of endotoxins has also been linked to reduced risks of allergic 
Cat exposure

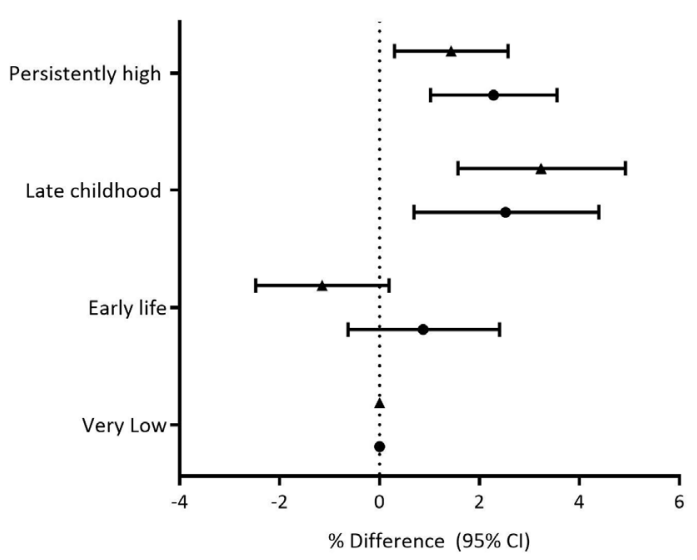

Rodent exposure

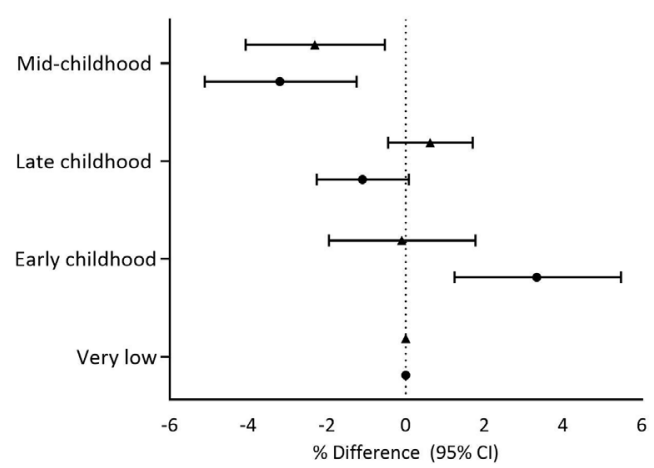

Dog exposure

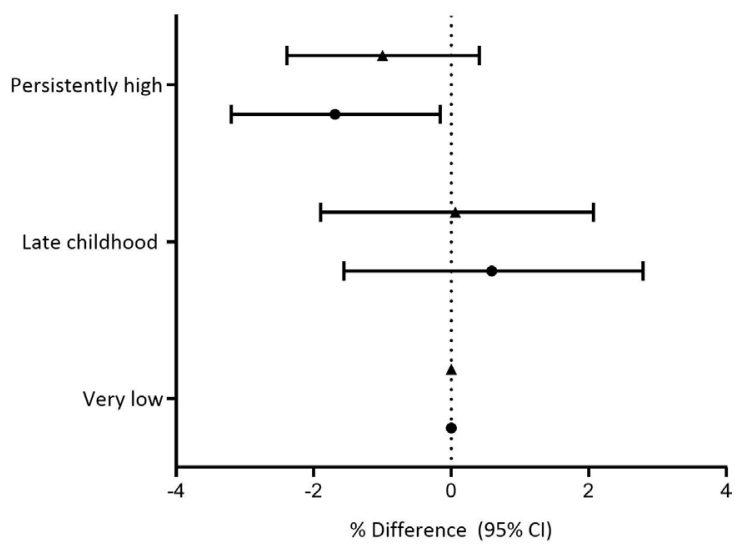

- Age 12

- Age 16

Figure 6 Associations of longitudinal patterns of cat, dog and rodent exposure with FVC level (\% difference) at ages 12 and 16 (adjusted for sex, log transformations of height, weight and age at medical examination, parental education, maternal and paternal allergy, breast feeding at 12 weeks, maternal smoking during pregnancy, indoor secondhand smoke at 1 year, $\mathrm{NO}_{2}$ concentration at the birth address, birth weight, use of gas for cooking at 3 months, dampness or mould in the child's home at 1 year, respiratory infections in the past 3 weeks before medical examination).

sensitisation and, less consistently, asthma. ${ }^{40-42}$ However, the relationship with lung function is unclear. A recent review ${ }^{43}$ reported weak reductions in $\mathrm{FEV}_{1}$ and $\mathrm{FVC}$ in relation to endotoxin exposure, but evidence was from occupational studies and in adults. This warrants more studies on pet exposure and lung function (growth) towards adolescence.

\section{Lung function and dampness or mould}

Associations with dampness or mould exposure have been reported for respiratory symptoms in children, but rarely with lung function in adolescence. Current dampness exposure was weakly associated with lower $\mathrm{FEV}_{1}$ in Dutch children 8-12 years old, ${ }^{16}$ but no associations were observed in Danish children aged 6-10 yearsd. ${ }^{44}$ Scarcity of evidence for associations between dampness or mould exposure and lung function (growth) in adolescents limits comparisons of our findings though we did not observe consistent associations. Higher lung function at age 12 was observed for early life exposure, but reduced growth between ages 12 and 16 was also observed as well as lower attained lung function for moderate and mid-childhood exposure patterns. It has been suggested that complex interactions of factors which are set in motion after inhaling mould fragments, toxins or spores can induce airway inflammation ${ }^{45}$ leading to restricted function of the lungs.

\section{Strengths and limitations}

We consider characterisation of exposure from pregnancy/birth until adolescence through longitudinal patterns, investigation of timing of exposure based on repeated exposure assessments and assessment of associations of these longitudinal patterns with lung function growth in adolescence as major strengths and novelty of our study.

Several limitations are considered. Exposure was assessed through self-reports and parents may under-report or overreport exposures due to knowledge of negative health effects. However, a multicohort validation study (including a subset of our cohort) comparing SHS exposure self-reports and measured air nicotine concentrations showed that selfreported SHS exposure provided valid estimates of reported residential exposure. ${ }^{46}$ Visible mould reports have also been shown to be highly correlated with airborne concentrations of fungal spores ${ }^{47}$ suggesting self-reported dampness or mould is a good exposure indicator. We performed analyses with raw spirometric data adjusting for age, sex, height and ethnicity. Alternatively, z-scores such as those provided by the Global Lung Initiative, taking into account age, sex, height and ethnicity, might have been used. Z-Scores might be better in adjusting for age, sex, height and ethnicity, ${ }^{48}$ but their interpretation is less straightforward. We adjusted all models for co-exposures in early life only and did not take into account co-exposures at different time points as confounders which may result in residual confounding. We used questionnaire responses to assess probability of exposure over time as actual levels of exposure were unknown. It has been shown that parental self-reported exposure is 
highly correlated with measured nicotine levels ${ }^{46}$; therefore, the effect of lack of levels of exposure data on our findings is likely small.

The 16-year lung function measurements were performed using two different spirometers in two different centres for logistical reasons. We performed a comparison study in healthy volunteers using the two spirometers to establish a calibration equation which we used to correct for systematic differences. ${ }^{49}$ We observed very high correlation between measurements from the two spirometers (0.98-0.99); moreover, we do not expect exposure patterns to be different for measurements performed by either of the spirometers so that effect of using different spirometers is likely very small. There were more children with highly educated parents, less children whose parents owned pets, less children who were exposed to SHS and more children who were breast fed for more than 12 weeks in the study population than in the baseline population due to loss to follow-up. Highly educated parents may be less likely to keep pets and less likely to smoke affecting generalisability of our findings. However, we do not expect the associations between predictors of the exposures of interest with lung function to be different from the entire PIAMA cohort. Generalisation beyond the Dutch population may, however, be limited in settings with different pet-keeping habits.

In conclusion, our study suggests that for lung function (growth), all time windows of exposure until age 12 may be relevant time windows for SHS exposure and pet exposure. Continued SHS exposure during childhood until age 12 could lead to reduced lung function growth and lower attained lung function, but pet exposure in late childhood may not adversely affect lung function. However, early life pet and dampness or mould exposure could lead to FVC growth deficits in adolescence. While observed effect sizes were small, these may cumulatively add up over time and translate into important clinical lung function deficits/increments at the population level.

This study advances our understanding of the relevance of the timing of exposure and could provide guidance on the timing and structure of interventions to improve respiratory health.

Acknowledgements The authors would like to thank PIAMA participants who contributed to the study.

Contributors $\mathrm{BB}$ and $\mathrm{HAS}$ were responsible for the conception and design of the PIAMA study. GHK, AHW, HAS and UG secured funding for the present study. EBM and UG designed the study and had full access to the data. EBM carried out the statistical analysis and wrote the initial draft of the manuscript. All authors (1) provided substantial contributions to the conception or design of the work, or the acquisition, analysis or interpretation of the data for the work, (2) revised the manuscript critically for important intellectual content and (3) approved the final version for submission.

Funding The research leading to these results has received funding from Dutch Lung Foundation (Project no. 4.1.14.001). In addition, the PIAMA study has received funding from the Netherlands Organization for Health Research and Development, the Netherlands Organization for Scientific Research, the Netherlands Asthma Fund, the Netherlands Ministry of Spatial Planning, Housing, and the Environment, and the Netherlands Ministry of Health, Welfare, and Sport (PIAMA).

Disclaimer The funders did not play any role in the design of the study, data collection, analysis and interpretation of data, and in writing the manuscript.

Competing interests GHK received grants from the Dutch Lung Foundation, grants from Ubbo Emmius Foundation, grants from Teva The Netherlands and grants from Stichting Astma Bestrijding, outside the submitted work. UG reports receiving grants from the Dutch Lung Foundation during the conduct of this study.

Patient consent for publication Parental/guardian consent obtained.

Ethics approval Ethical approval was obtained from participating institutes (ethical approval nos.: Rotterdam, MEC 132.636/1994/39 and 137.326/1994/130; Groningen, MEC 94/08/92; Utrecht, MEC-TNO 95/50).
Provenance and peer review Not commissioned; externally peer reviewed. Data availability statement Data are available on reasonable request.

ORCID iD

Edith B Milanzi http://orcid.org/0000-0002-7305-6035

\section{REFERENCES}

1 Chapman RS, Hadden WC, Perlin SA. Influences of asthma and household environment on lung function in children and adolescents: the third National Health and Nutrition Examination Survey. Am J Epidemiol 2003;158:175-89.

2 Gilliland FD, Berhane K, McConnell R, et al. Maternal smoking during pregnancy, environmental tobacco smoke exposure and childhood lung function. Thorax 2000;55:271-6.

3 Tager IB, Weiss ST, Muñoz A, et al. Longitudinal study of the effects of maternal smoking on pulmonary function in children. N Engl J Med 1983;309:699-703.

4 Chan-Yeung M, Dimich-Ward H. Respiratory health effects of exposure to environmental tobacco smoke. Respirology 2003;8:131-9.

5 Dijkstra L, Houthuijs D, Brunekreef B, et al. Respiratory health effects of the indoor environment in a population of Dutch children. Am Rev Respir Dis 1990;142:1172-8.

6 Moshammer H, Hoek G, Luttmann-Gibson H, et al. Parental smoking and lung function in children: an international study. Am J Respir Crit Care Med 2006;173:1255-63.

7 Schultz ES, Hallberg J, Bellander T, et al. Early-life exposure to traffic-related air pollution and lung function in adolescence. Am J Respir Crit Care Med 2016;193:171-7.

8 Thacher JD, Schultz ES, Hallberg J, et al. Tobacco smoke exposure in early life and adolescence in relation to lung function. Eur Respir J 2018;51. doi:10.1183/13993003.02111-2017

9 Dai X, Dharmage SC, Lowe AJ, et al. Early smoke exposure is associated with asthma and lung function deficits in adolescents. J Asthma 2017;54:662-9.

10 Corbo GM, Agabiti N, Forastiere F, et al. Lung function in children and adolescents with occasional exposure to environmental tobacco smoke. Am J Respir Crit Care Med 1996;154:695-700.

11 Sherrill DL, Martinez FD, Lebowitz MD, et al. Longitudinal effects of passive smoking on pulmonary function in New Zealand children. Am Rev Respir Dis 1992;145:1136-41.

12 Fernández-Plata R, Rojas-Martínez R, Martínez-Briseño D, et al. Effect of passive smoking on the growth of pulmonary function and respiratory symptoms in schoolchildren. Rev Invest Clin 2016;68:119-27.

13 Lebowitz MD, Sherrill D, Holberg CJ. Effects of passive smoking on lung growth in children. Pediatr Pulmonol 1992;12:37-42.

14 Collin SM, Granell R, Westgarth C, et al. Associations of PET ownership with wheezing and lung function in childhood: findings from a UK birth cohort. PLOS One 2015;10:e0127756

15 LW H, Qian Z, Dharmage SC, et al. Pre-natal and post-natal exposure to PET ownership and lung function in children: The Seven Northeastern Cities Study. Indoor air 2017;27:1177-89.

16 Cuijpers CEJ, Swaen GMH, Wesseling G, et al. Adverse-effects of the indoor environment on respiratory health in primary-school children. Environ Res 1995;68:11-23.

17 Wang L, Pinkerton KE. Detrimental effects of tobacco smoke exposure during development on postnatal lung function and asthma. Birth Defects Res C Embryo Today 2008;84:54-60.

18 Wijga AH, Kerkhof M, Gehring U, et al. Cohort profile: the prevention and incidence of asthma and mite allergy (PIAMA) birth cohort. Int J Epidemiol 2014;43:527-35.10.1093/ije/dys231

19 Nagin DS, Odgers CL. Group-based trajectory modeling in clinical research. Annu Rev Clin Psychol 2010;6:109-38.

20 Bekkers MB, Wijga $\mathrm{AH}$, Gehring U, et al. BMI, waist circumference at 8 and 12 years of age and FVC and FEV 1 at 12 years of age; the PIAMA birth cohort study. BMC Pulm Med 2015:15:39.

21 Milanzi EB, Koppelman GH, Smit HA, et al. Air pollution exposure and lung function until age 16 years: the PIAMA birth cohort study. Eur Respir J 2018;52. doi:10.1183/13993003.00218-2018. [Epub ahead of print: 2709 2018].

22 Miller MR, Hankinson J, Brusasco V, et al. Standardisation of spirometry. Eur Respir J 2005:26:319-38

23 Dockery DW, Berkey CS, Ware JH, et al. Distribution of forced vital capacity and forced expiratory volume in one second in children 6 to 11 years of age. Am Rev Respir Dis 1983;128:405-12.

24 Raizenne M, Neas LM, Damokosh Al, et al. Health effects of acid aerosols on North American children: pulmonary function. Environ Health Perspect 1996;104:506-14.

25 Almqvist C, Egmar A-C, Hedlin G, et al. Direct and indirect exposure to petsrisk of sensitization and asthma at 4 years in a birth cohort. Clin Exp Allergy 2003:33:1190-7.

26 Bono R, Nebiolo F, Bugiani M, et al. Effects of tobacco smoke exposure on lung growth in adolescents. J Expo Anal Environ Epidemiol 1998;8:335-45. 
27 Ogbuanu IU, Karmaus W, Arshad SH, et al. Effect of breastfeeding duration on lung function at age 10 years: a prospective birth cohort study. Thorax 2009;64:62-6.10.1136/thx.2008.101543

28 Moshammer $\mathrm{H}$, Fletcher $\mathrm{T}$, Heinrich J, et al. Gas cooking is associated with small reductions in lung function in children. Eur Respir J 2010;36:249-54.

29 Corbo GMet al. Effect of gas cooking on lung function in adolescents: modifying role of sex and immunoglobulin E. Thorax 2001;56:536-40.

30 Edwards CA, Osman LM, Godden DJ, et al. Relationship between birth weight and adult lung function: controlling for maternal factors. Thorax 2003;58:1061-5.

31 Gehring U, Beelen R, Eeftens M, et al. Particulate matter composition and respiratory health: the PIAMA birth cohort study. Epidemiology 2015;26:300-9.

32 von Elm E, Altman DG, Egger M, et al. The strengthening the reporting of observational studies in epidemiology (STROBE) statement: guidelines for reporting observational studies. Int J Surg 2014;12:1495-9.

33 Pinkerton KE, Harbaugh M, Han MK, et al. Women and lung disease. Sex differences and global health disparities. Am J Respir Crit Care Med 2015;192:11-16.

$34 \mathrm{Hu} \mathrm{L-W}$, Yang M, Chen S, et al. Effects of in utero and postnatal exposure to secondhand smoke on lung function by gender and asthma status: The Seven Northeastern Cities (SNEC) study. Respiration 2017;93:189-97.

35 Lødrup Carlsen KC, Roll S, Carlsen K-H, et al. Does pet ownership in infancy lead to asthma or allergy at school age? Pooled analysis of individual participant data from 11 European birth cohorts. PLoS One 2012;7:e43214.

36 Wang X, Wypij D, Gold DR, et al. A longitudinal study of the effects of parental smoking on pulmonary function in children 6-18 years. Am J Respir Crit Care Med 1994;149:1420-5.

37 Hollams EM, de Klerk NH, Holt PG, et al. Persistent effects of maternal smoking during pregnancy on lung function and asthma in adolescents. Am J Respir Crit Care Med 2014:189:401-7.
38 The health consequences of involuntary exposure to tobacco smoke: a report of the Surgeon General. Atlanta (GA, 2006.

39 Martinez-Gonzalez I, Steer CA, Takei F. Lung ILC2s link innate and adaptive responses in allergic inflammation. Trends Immunol 2015;36:189-95.

40 Hesselmar B, Aberg N, Aberg B, et al. Does early exposure to cat or dog protect against later allergy development? Clin Exp Allergy 1999;29:611-7.

41 Ownby DR, Johnson CC, Peterson EL. Exposure to dogs and cats in the first year of life and risk of allergic sensitization at 6 to 7 years of age. JAMA 2002;288:963-72.

42 Ownby DR, Peterson EL, Wegienka G, et al. Are cats and dogs the major source of endotoxin in homes? Indoor Air 2013;23:219-26.

43 Farokhi A, Heederik D, Smit LAM. Respiratory health effects of exposure to low levels of airborne endotoxin - a systematic review. Environmental Health 2018;17.

44 Holst GJ, Høst A, Doekes $G$, et al. Allergy and respiratory health effects of dampness and dampness-related agents in schools and homes: a cross-sectional study in Danish pupils. Indoor Air 2016;26:880-91.

45 Mendell MJ, Mirer AG, Cheung K, et al. Respiratory and allergic health effects of dampness, mold, and dampness-related agents: a review of the epidemiologic evidence. Environ Health Perspect 2011;119:748-56.10.1289/ehp.1002410

46 Gehring U, Leaderer BP, Heinrich J, et al. Comparison of parental reports of smoking and residential air nicotine concentrations in children. Occup Environ Med 2006;63:766-72.

47 Haas D, Habib J, Galler H, et al. Assessment of indoor air in Austrian apartments with and without visible mold growth. Atmos Environ 2007:41:5192-201.

48 Quanjer PH, Stanojevic S, Cole TJ, et al. Multi-ethnic reference values for spirometry for the 3-95-yr age range: the global lung function 2012 equations. Eur Respir J 2012:40:1324-43.

49 Milanzi EB, Koppelman GH, Oldenwening $M$, et al. Considerations in the use of different spirometers in epidemiological studies. Environ Health 2019;18. 